\title{
A district service for bereavement care
}

\author{
Colin Murray Parkes, Senior Lecturer in Psychiatry, London Hospital Medical \\ College, London E1 2AD
}

Bereavement counselling is one of the few examples of preventive psychiatry to have proved its worth in well conducted random allocation studies (Raphael, 1977; Parkes, 1981). If, as the work of Paykel (1974) and Brown \& Harris (1978) suggests, major losses are the life events most of ten associated with the onset of clinical depression, then psychiatrists would do well to involve themselves in the work of any organisation which aims to meet the psychological needs of the bereaved.

Cruse is currently celebrating 30 years of bereavement care. It is unique in the world in providing a cost effective body of over 3,000 carefully selected and trained volunteer counsellors who work closely with professional social workers, psychologists and psychiatrists to offer counselling to all bereaved people who seek its help.

Originally the services of Cruse were offered only to widows and their children. Widows still comprise the majority of its members. In recent years, however, it has grown in size and scope to serve widowers, parents, siblings, homosexual partners, in fact the full range of people bereaved by death. They are helped by 160 branches of Cruse across the United Kingdom.

Counsellors from Cruse have given support to people bereaved in all the major disasters in recent years and are hosting a government working party on planning for future disasters. Through its training officer and area organisers, Cruse trains volunteers and professionals in the techniques of counselling. It publishes a journal, Bereavement Care, for all with an interest in counselling and has produced a range of special publications.

Cruse receives a government grant from the DHSS and has links with MPs from each party to whom it comments on legislation affecting the bereaved. It is governed by a Council and by its central Training and Research Committees, each of which includes one or more psychiatrists among its members. In fact psychiatrists have been involved in the work of Cruse from the outset and have helped to ensure that the organisation provides a great deal more than 'tea and sympathy'.
Psychiatrists who are willing to give time to Cruse are needed in many of the branches. They have a part to play in the selection, training and support of counsellors, as well as providing psychiatric help to the small minority of people who develop frank mental illnesses after bereavement or whose psychological difficulties are beyond the skills of the 'front line' of volunteer counsellors and social workers.

Short longitudinal studies and random allocation techniques have demonstrated their worth as methods of research and recent studies of the endocrine and immune response to bereavement have brought home the importance of further work. The field is developing rapidly and has attracted psychiatrists with a wide range of special interests. Child psychiatrists and family psychiatrists have much to contribute and learn here, so too have psychiatrists with an interest in old age, forensic work and mental handicap as well as psychotherapists and general psychiatrists.

Cruse now has the structure to provide practical preventive psychiatry in all parts of Britain. To do this properly it needs the help of one or more members of each district psychiatric team and we shall be glad to learn of your interest. For information about local branches please phone (01) $940-4818$ or write to The Director, Cruse House, 126 Sheen Road, Richmond, Surrey TW9 2JH.

\section{References}

Brown, G. W. \& HARRIS, T. (1978) Social Origins of Depression: A Study of Psychiatric Disorders in Women. London: Tavistock.

PARKES, C. M. (1981) Evaluation of a bereavement service. Journal of Preventive Psychiatry, 1, 179.

PAYKel, E. S. (1974) Life stress and psychiatric disorder: applications of the clinical approach. In Stressful Life Events: Their Nature Effects (eds. B. S. Dohrenwend \& B. P. Dohrenwhend. New York: Wiley.

Raphael, B. (1977) Preventive intervention with the recently bereaved. Archives of General Psychiatry, 34, 1450. 